\title{
Dairy cow preference for access to an outdoor pack in summer and winter
}

\author{
A. M. C. Smid, ${ }^{1}$ E. E. A. Burgers, ${ }^{1,2}$ D. M. Weary, ${ }^{1}$ E. A. M. Bokkers,${ }^{2}$ and M. A. G. von Keyserlingk ${ }^{1 *}$ \\ ${ }^{1}$ Animal Welfare Program, Faculty of Land and Food Systems, University of British Columbia, 2357 Main Mall, Vancouver, BC, V6T 1Z6 Canada \\ ${ }^{2}$ Animal Production Systems Group, Wageningen University \& Research, PO Box 338, $6700 \mathrm{AH}$, Wageningen, the Netherlands
}

\section{ABSTRACT}

The aim of our study was to test the preference of freestall-housed dairy cows to access an outdoor deepbedded open pack (versus remaining inside the freestall barn) in the summer and winter. A secondary aim was to investigate how preference for outdoor access influenced feeding, lying, and stall perching behavior. Eight groups of pregnant, lactating cows were tested in the summer and 9 groups in the winter. During both experiments, groups were allowed to stabilize for 5 $\mathrm{d}$, followed by $2 \mathrm{~d}$ of baseline observations (baseline phase). Habituation to the outdoor pack took place for the next $2 \mathrm{~d}$. Cows were then provided free access to the outdoor pack continuously for $5 \mathrm{~d}$ (choice phase). During the choice phase, in addition to feeding and perching behavior (recorded while cows were inside the barn), cow location (i.e., in the freestall pen or on the outdoor pack) was also noted. We used HOBO data loggers (Onset Computer Corp., Bourne, MA) to automatically record lying behavior during baseline and choice phases. Cows spent (mean \pm standard error; minimum to maximum in parentheses) $25.3 \pm 4.3 \%$ (8.0 to $44.5 \%$ ) of their time outside in the summer and $1.8 \pm 0.6 \%$ (0.1 to $4.1 \%$ ) in the winter. In the summer, cows spent more time on the outdoor pack during night $(50.0 \pm 8.4 \%$ between 2000 and $0600 \mathrm{~h}$ ) than during the day $(3.3 \pm 1.3 \%$ between 0600 and $2000 \mathrm{~h})$. In the winter, we found no effect of time of day on time spent outside $($ day $=1.7 \pm 0.7 \%$; night $=2.1 \pm 1.0 \%)$. Precipitation decreased the time cows spent outside during summer nights. During winter days, precipitation and increasing wind speeds decreased the time cows spent outside. In the summer, time spent feeding was higher during the baseline phase $(18.7 \pm 0.3 \%)$ than during the choice phase $(17.4 \pm 0.3 \%)$. During the winter, no difference in feeding time was found between the 2

Received May 3, 2018.

Accepted October 17, 2018.

*Corresponding author: nina@mail.ubc.ca phases (baseline $=18.7 \pm 0.3 \%$; choice $=18.4 \pm 0.3 \%$ ) During the summer, cows spent more time perching during the baseline phase $(6.5 \pm 0.5 \%)$ than during the choice phase $(3.6 \pm 0.5 \%)$ and this tended to be true during the winter (baseline $=5.5 \pm 0.7 \%$; choice $=4.5 \pm 0.7 \%$ ). Daily lying time did not differ between the baseline and choice phases in either the summer (baseline $=59.6 \pm 0.9 \%$; choice $=57.7 \pm 0.9 \%$ ) or winter (baseline $=63.0 \pm 1.2 \%$; choice $=62.6 \pm 1.2 \%$ ). When on the outdoor pack, cows spent $53.7 \%( \pm 5.6)$ of the time lying during the summer and $4.7 \%( \pm 2.5)$ during the winter. In conclusion, during the summer, cows displayed a partial preference to be outside on a deep-bedded open pack when given the opportunity, especially during the night, but in the winter, cows spent little time on the outdoor pack.

Key words: animal welfare, outdoor area, alternative housing, exercise lot

\section{INTRODUCTION}

A growing body of evidence has shown that the public considers pasture access for dairy cows important (Schuppli et al., 2014; Hötzel et al., 2017) and that cows value access to pasture, especially at night (e.g., Legrand et al., 2009; Charlton et al., 2013; von Keyserlingk et al., 2017). Cows may use indoor housing as protection from rainfall (Legrand et al., 2009; Charlton et al., 2011a, 2013) and solar radiation (Schütz et al., 2009).

Pasture access is not always feasible due to a lack of available pasture on some farms and environmental constraints, such as high rainfall, which can render the soil soft and susceptible to damage from cows. An alternative to pasture is a deep-bedded outdoor pack. One advantage of an outdoor pack is that it can be used year round, without concerns about grass growth, soil compaction, and so on. In addition, space requirements for an outdoor pack are generally lower than for pasture.

Providing cows with free access to an outdoor pack could have beneficial effects on their health and behavior. When indoor-housed cows were given a choice 
between a freestall pen and an indoor open pack, they spent more time lying and standing with 4 feet in the open pack (Fregonesi et al., 2009). Those authors also reported that cows spent less time standing on wet concrete and perching (i.e., standing with the 2 front feet in the lying stall) when housed on an indoor open pack, behaviors that put cows at risk for lameness (Galindo and Broom, 2000). Another study confirmed that daily perching time decreased when cows were given access to an outdoor open sand pack or pasture (Smid et al., 2018). One concern with providing pasture access is that this will result in decreased feed intake (Schuppli et al., 2014). One previous study (Legrand et al., 2009) found that cows decreased their TMR intake (by 2.9 $\mathrm{kg}$ of $\mathrm{DM} / \mathrm{d}$ ) when given access to pasture, but another study (Chapinal et al., 2010) found no reduction in TMR intake when cows were housed on pasture at night.

To date, most work on preference of cows to access the outdoors has been conducted under summer conditions (when pasture is most commonly offered), so the aim of our first experiment was to investigate dairy cow preference for access to an outdoor pack versus remaining inside a freestall barn in the summer. However, one advantage of an outdoor pack is that access can be offered year round, so the aim of the second experiment was to investigate preference in the winter. By providing cows with access to an outdoor area that did not contain grass, we also provided insight into preference for outdoor access independent of grazing. We predicted that cows would prefer to spend time outside at night in the summer, and that this preference for nighttime access would be absent during the winter. In addition, we predicted that cows would spend less time outside when the weather was hot or rainy (in the summer) and rainy or windy (in the winter). We also predicted that daily feeding and lying time would not change but that cows would spend less time perching when given access to an outdoor pack regardless of season.

\section{MATERIALS AND METHODS}

\section{Cows and Treatment}

The summer experiment took place from June to August 2016 and the winter experiment from October 2016 to February 2017. Both experiments were carried out at the Dairy Education and Research Centre (Agassiz, BC, Canada) of the University of British Columbia. The University of British Columbia Animal Care Committee approved both experiments and all procedures (Protocol A15 - 0082).
For the 2 experiments, a total of 96 and 108 pregnant, late-lactation (>100 DIM) Holstein cows were selected from the herd and assigned to 8 (summer experiment) and 9 (winter experiment) groups (i.e., 12 animals/ group), respectively. Cows were randomly assigned to groups, blocking for parity, with some balancing to achieve similar DIM, 305-d projected milk production, and experience with an outdoor pack. In the summer and winter experiments, parity averaged (mean \pm SD) $2.3 \pm 0.1$ and $2.5 \pm 0.3 ;$ DIM was $240 \pm 17$ and $232 \pm$ 31 ; projected 305-d milk production was $11,310 \pm 159$ and $10,958 \pm 466 \mathrm{~kg}$; and the number of animals with previous experience on an outdoor pack was $2.5 \pm 1.2$ and $6.1 \pm 1.5$, respectively. The majority of the animals had spent time on pasture as growing heifers, and some had also been kept on pasture during dry periods. Two experienced observers assessed cows before group formation for body condition using a 5-point scale (1 $=$ thin, $5=$ obese) with quarter-point increments (following Edmonson et al., 1989) and gait using a 5-point scale $(1=$ healthy, $5=$ severely lame; following Flower and Weary, 2006). Cow BCS averaged $3.3 \pm 0.1$ and 3.4 \pm 0.3 and gait score averaged $1.9 \pm 0.2$ and $2.0 \pm 0.2$ for the summer and winter periods, respectively. Thin cows (i.e., BCS <2.5) and severely lame cows (gait score 4 and 5) were not included in the study.

We used a within-group comparison, as it allowed us to directly investigate the effect of the time spent outdoors on various behaviors. This approach would not have accounted for within-group factors that might have changed over time. However, given that the cows were only tested for $7 \mathrm{~d}$, the effects of time on DIM, milk yield, and so on were likely minimal.

Groups were assigned to 1 of 2 experimental pens for $14 \mathrm{~d}$. Each pen had access to a separate outdoor pack (see Smid et al., 2018 for the schematic of the experimental setup). Groups were given $5 \mathrm{~d}$ to stabilize before being provided access to the outdoor pack. Thereafter, starting after the animals came back from morning milking, groups were housed indoors for another $2 \mathrm{~d}$ and baseline observations of feeding, perching, and lying behavior were made (baseline phase). Groups were then given access to the outdoor pack during a 2-d habituation period. To ensure that cows were familiar with the outdoor pack they were moved outside at 1030, 1400, 2000, 2200, and $0430 \mathrm{~h}$ if not already outdoors. After this habituation period, starting when cows returned to their pen after morning milking, cows were given free continuous access to the outdoor pack for $5 \mathrm{~d}$ (choice phase). Two groups were tested at once, but were staggered in time such that the second group started when the baseline phase of the first group had 
finished. Thus, the 2 groups did not have access to the outdoor packs at the same time.

\section{Housing, Management, and Diet}

Indoor Area. The 2 indoor pens were located in a mechanically ventilated (72" Artex Storm Fan, Artex Barn Solutions, Abbotsford, BC, Canada) woodenframe freestall barn $(42 \times 93 \mathrm{~m})$ with a north-south orientation and curtained sidewalls. Each pen consisted of 12 lying stalls, configured in 3 rows of 4 stalls that were filled with approximately $40 \mathrm{~cm}$ of washed river sand. Stalls were divided by Dutch-style partitions spaced $1.2 \mathrm{~m}$ wide center-to-center, with the neck rail placed $1.3 \mathrm{~m}$ above the stall surface and $1.4 \mathrm{~m}$ from the inside of the rear curb. The brisket board was placed $1.8 \mathrm{~m}$ from the inside of the curb, which was $0.2 \mathrm{~m}$ high as measured from the alley floor. The concrete alleys were cleaned a minimum of 6 times daily with an automated scraper; crossover alleys were manually cleaned twice a day. Each pen had a headlock feed barrier with 12 headlocks per pen, $60 \mathrm{~cm}$ wide center-to-center.

Cows were fed a TMR formulated following the NRC (2001) guidelines to meet or exceed the requirements of a $658-\mathrm{kg}$ Holstein producing $36 \mathrm{~kg}$ of milk daily. During the summer experiment, the TMR consisted of $30 \%$ grass silage, $49 \%$ concentrate mash, $14 \%$ corn silage, $6 \%$ grass hay, and $1 \%$ wheat straw on a DM basis; during the winter experiment, the TMR consisted of $34 \%$ corn silage, $44 \%$ concentrate mash, $7 \%$ grass silage, $7 \%$ grass hay, $6 \%$ alfalfa hay, and $2 \%$ wheat straw on a DM basis. The TMR was available ad libitum inside throughout both experiments. In both experiments, fresh feed was provided between 0615 and 0645 $\mathrm{h}$ and between 1615 and $1645 \mathrm{~h}$ and pushed up at approximately 1045, 1845, and $2230 \mathrm{~h}$; feed leftovers were taken away at approximately $0530 \mathrm{~h}$. Water was available via a self-filling water trough $(1.97 \times 0.54 \mathrm{~m})$ located on the crossover alley.

During both experiments, animals were milked twice daily in a double-12 parallel milking parlor between 0615 and $0645 \mathrm{~h}$ in the morning and between 1615 and $1645 \mathrm{~h}$ in the afternoon. Animals that were outside were moved from the outdoor pack to the parlor; animals that were inside were moved from their pen to the parlor.

Outdoor Area. The 2 outdoor packs each measured $144 \mathrm{~m}^{2}$ and had a gravel surface bedded with a base layer of approximately $20 \mathrm{~cm}$ of sand and a top layer of approximately $25 \mathrm{~cm}$ of pole peelings, a by-product of the wood industry. The pole peelings were made up of mainly fir with some cedar. The outdoor packs were lined with electric fencing. One self-filling water trough
$(1.25 \times 0.84 \mathrm{~m})$ was provided in each outdoor pack. Outdoor paths leading to the packs were covered with rubber mats. The paths and the outdoor pack were cleaned daily every afternoon when the cows were in the milking parlor.

\section{Behavioral Measures}

During the baseline and choice phases, cows were recorded by video. Three dome video cameras (Panasonic WV-CW504SP, Sentinel Ultra-zoom w/Pan 1070 outdoor video camera, Sandpiper Technologies Inc., Manteca, CA) were attached on the outdoor wall of the barn, $6 \mathrm{~m}$ above the ground. The middle camera provided an overview of the entrances of both outdoor packs and the other 2 cameras each provided an overview of a single pack. These cameras were placed $6.1 \mathrm{~m}$ to the left and $7.0 \mathrm{~m}$ to the right of the middle camera. In addition, a dome camera was attached $8 \mathrm{~m}$ above the indoor alleys that connected the outdoor areas with the experimental pens to allow the observation of cows in the indoor alleys. Above each experimental pen, a dome video camera was positioned at a height of $8 \mathrm{~m}$ to provide an overview of the indoor lying area. Another video camera (Panasonic WVCP-470, Panasonic Corporation of North America, Newark, NJ) was placed 6 $\mathrm{m}$ above the feed bunk of each experimental pen. All video recordings were stored using a GeoVision 1480 digital recorder (USA Vision Systems, Irvine, CA). Infrared lights (BR38 Red Incandescent Flood Light 100 W, Globe Electric Co. Inc., Montréal, QC, Canada) were placed adjacent to all in- and outside cameras to facilitate the observation of the cows during the night. Each cow had its hair dyed with a unique symbol on both of her sides and on her back to facilitate individual recognition.

Feeding and stall perching behavior of the cows inside the freestall barn was scored using 5-min scan sampling from video during both the baseline and choice phases. Feeding was defined as the cow having her head completely through the headlock. A cow was considered perching if she was standing with only her 2 front feet in the lying stall. In addition, during the choice phase, the location of animals (i.e., in the pen, on the outdoor pack, in the indoor or outdoor alley) was also scored using 5-min video scan sampling.

We used HOBO data loggers (HOBO Pendant G, Onset Computer Corp., Cape Cod, MA; validated by Ledgerwood et al., 2010) to quantify lying times (UBC AWP, 2013). The data loggers, attached to one of the rear legs of the cow, were programmed to record the posture of the cow (i.e., lying or standing) in 1-min intervals. The loggers were attached during milking at 
least $1 \mathrm{~d}$ before the beginning of the baseline phase and were removed after the experimental period.

\section{Climatic Measures}

For each experimental day, hourly mean air temperature $\left({ }^{\circ} \mathrm{C}\right)$ and wind speed $(\mathrm{m} / \mathrm{s})$ and the hourly maximum relative humidity (\%) and total precipitation $(\mathrm{mm})$ were recorded at a weather station $0.4 \mathrm{~km}$ from the test barn. The temperature-humidity index (THI) was calculated as THI $=(1.8 \mathrm{~T}+32)-[(0.55-$ $0.0055 \mathrm{RH}) \times(1.8 \mathrm{~T}-26)]$, where $\mathrm{T}=$ air temperature $\left({ }^{\circ} \mathrm{C}\right)$ and $\mathrm{RH}=$ relative humidity $(\%)$ (Ravagnolo et al., 2000). Daily temperature, wind speed, and relative humidity averaged (mean $\pm \mathrm{SD}$; numbers are given for the summer and winter experiment, respectively): 18.4 $\pm 2.3^{\circ} \mathrm{C}$ (range $=13.9-23.5^{\circ} \mathrm{C}$ ) and $5.1 \pm 4.6^{\circ} \mathrm{C}$ (range $\left.=-4.3-13.5^{\circ} \mathrm{C}\right) ; 4.9 \pm 1.3 \mathrm{~m} / \mathrm{s}($ range $=2.5-8.2 \mathrm{~m} / \mathrm{s})$ and $8.0 \pm 6.3 \mathrm{~m} / \mathrm{s}($ range $=1.3-23.9 \mathrm{~m} / \mathrm{s}) ; 72.8 \pm$ $7.2 \%$ (range $=57.1-88.4 \%)$ and $78.9 \pm 16.6 \%$ (range $=$ 26.7-94.5\%). Precipitation was recorded on 14 of the 36 experimental days during the summer experiment and on 24 of the 39 experimental days during the winter. Precipitation averaged $2.7 \pm 4.6 \mathrm{~mm}$ (range $=0.2-16.9$ $\mathrm{mm}$ ) during the summer experiment and $9.9 \pm 10.6 \mathrm{~mm}$ (range $=0.3-37.4 \mathrm{~mm}$ ) during the winter experiment on days with precipitation. The THI averaged $63.5 \pm$ 3.2 (range $=57.0-70.2$ ) during the summer experiment and $43.4 \pm 6.7$ (range $=30.8-56.4$ ) during the winter experiment.

\section{Statistical Analyses}

A total of 7 cows (4 from the summer and 3 from the winter experiment) became lame during the study and were excluded from the analyses. One cow (from the winter experiment) refused to go outdoors during the habituation phase and was excluded from the analyses. On 2 occasions (once during the summer and once during the winter), a nonexperimental cow was inadvertently added to the experimental group (on the last day of the choice phase in the summer experiment, and on the first day of the choice phase in the winter experiment). For one group in the winter experiment, on one occasion (on the second day of the choice phase), cows were mixed with cows of an adjacent pen. The data from these days were excluded from the analyses. An additional 3 experimental days were lost $(1 \mathrm{~d}$ from 3 different groups) during the summer experiment: on 2 occasions due to problems with the gates that separated the outdoor from the indoor area and on another occasion due to several cows being out of the pen for hoof trimming. Malfunction of a camera resulted in the loss of feeding and perching behavior data for 1 group for
$2 \mathrm{~d}$ during the summer experiment. Extreme weather (snow and wind) during the winter experiment resulted in the doors that provided access to the outdoor pack being closed for $4 \mathrm{~d}$ ( $1 \mathrm{~d}$ for one group, $3 \mathrm{~d}$ for the other group).

Data were summarized by group and phase and analyzed using SAS (version 9.4, SAS Institute, Institute Inc., Cary, NC), treating group as the experimental unit. All results are reported as a percentage of time available for observation (i.e., not including times when cows were away for milking, health checks, and so on). In addition, with regard to the analysis of time spent inside or on the outdoor pack, observations in which cows were standing in the indoor (i.e., the alley connecting the freestall to the outdoor area) or outdoor alley were also removed. All analyses were run separately for the summer and winter experiments. Using the UNIVARIATE procedure, the histograms and Q-Q plots of all variables were visually assessed for normality. In addition, all model residuals were visually assessed and were normally distributed. For the analysis of time spent inside and outside, we analyzed the data over the full daily period as well as separately for the day (0600-2000 h) and night (2000-0600 h). Differences in time cows spent outside during the day and night were tested using a paired $t$-test, using the average time groups spent outside during the day and night over the complete choice phase (i.e., 5 d). Two out of the 9 groups of the winter experiment were extreme outliers, spending much more time outside than the other groups. These 2 groups were not included in the statistical analysis, but the results are reported descriptively in the text.

The MIXED procedure in SAS was used to test the differences in time spent in different behaviors (i.e., feeding, perching, and lying) during the baseline and choice phases, with phase included as a fixed effect and group as random effect. A Spearman correlation was used to investigate the correlation between the weather variables (i.e., air temperature, wind speed, relative humidity, precipitation, and THI) by season. Some of the environmental measures (e.g., temperature and THI) were highly correlated $(\mathrm{r}>0.7)$. In these cases, we kept in the analysis only the correlate for which we had the strongest prediction. This resulted in dropping temperature, relative humidity, and wind speed for the summer experiment, and relative humidity and THI for the winter experiment. Data were summarized by group and day; the effects of the weather conditions on the preference for outdoor access was tested using a mixed model with day as a repeated measure and group as subject. Significance was declared for $P<0.05$ and a trend for $P<0.10$. All means and standard errors reported below are derived from model output. 


\section{RESULTS}

\section{Time Spent in the Freestall Versus} on the Outdoor Pack

Cows averaged (mean $\pm \mathrm{SE}$; minimum-maximum) $25.3 \pm 4.3 \%$ (range $=8.0-44.5 \%$ ) of their time on the outdoor pack in the summer and $1.8 \pm 0.6 \%$ (range: $=0.1-4.1 \%$ ) in the winter (Figure 1). In the summer, cows spent more time outside at night $(50.0 \pm 8.4 \%$; range $=15.8-84.2 \%)$ than during the day $(3.3 \pm 1.3 \%$; range $\left.=0.9-11.4 \% ; \mathrm{t}_{7}=-5.56, P<0.001\right)$. Groups varied in time spent outside in the winter, as 7 of the 9 groups spent little time outside during the day $(1.7 \pm$ $0.7 \%$; range $=0.0-5.1 \%)$ or night $(2.1 \pm 1.0 \%$; range $\left.=0.0-7.1 \% ; \mathrm{t}_{6}=-0.41, P=0.693\right)$ and the 2 other groups spent much more time outside during the day (averaging $8.9 \%$ in one group and $23.4 \%$ in the other) and especially so at night (50.7 and $46.8 \%$ for the 2 groups, respectively).

\section{Feeding, Perching, and Lying Behavior}

Cows spent more time feeding during the baseline versus choice phase in the summer $\left(F_{1,7}=12.10, P<\right.$ 0.02 ; Figure 2). During the winter, we found no differ-

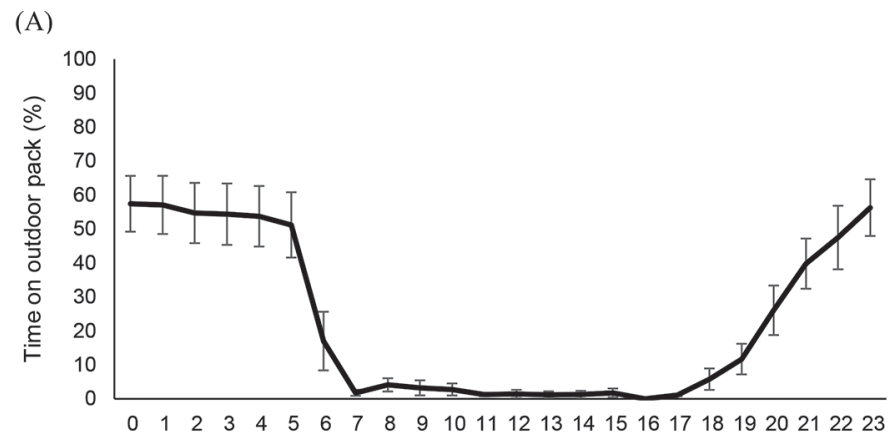

(B)

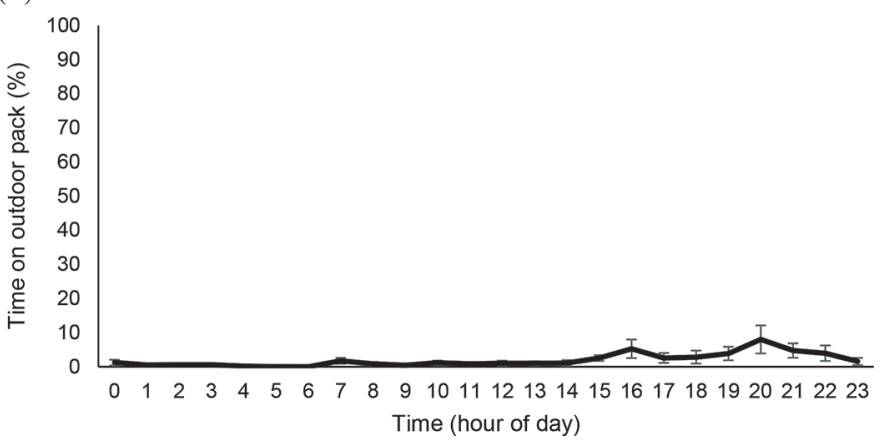

Figure 1. Mean $( \pm \mathrm{SE})$ percentage of time groups of lactating dairy cows (summer, $\mathrm{n}=8$ groups; winter, $\mathrm{n}=7$ groups) spent on the outdoor pack when provided a free choice between a freestall barn and an outdoor pack during the summer (A) and winter (B).
(A)



(B)

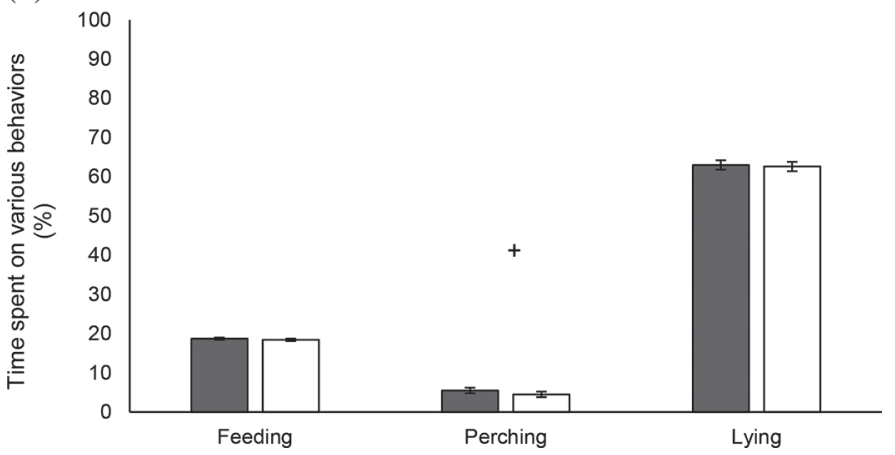

Figure 2. Mean ( $\pm \mathrm{SE}$ ) time groups of lactating dairy cows (summer, $\mathrm{n}=8$ groups; winter, $\mathrm{n}=7$ groups) spent feeding, perching, and lying, expressed as a percentage of the time available for observation (i.e., when not away from the pen for milking, and so on) during the baseline (gray bar) and choice (white bar) phases in the summer (A) and winter $(\mathrm{B})$.

ence in feeding time between the phases. Time spent perching was higher during the baseline versus choice phase in the summer $\left(F_{1,7}=21.59 ; P<0.01\right)$ and tended to be higher in the baseline versus the choice phase in the winter $\left(F_{1,6}=5.58, P=0.056\right)$. Daily lying time did not differ between baseline and choice phases during either the summer or winter. When on the outdoor pack, cows averaged $53.7 \%( \pm 5.6)$ of the time lying down during the summer and $4.7 \%( \pm 2.5)$ during the winter.

\section{Environmental Conditions}

During summer nights, cows spent less time outside when it was raining, and time outside decreased by 14 $\pm 5.5 \%$ for every $1-\mathrm{mm}$ increase in hourly rainfall $\left(F_{1,26}\right.$ $=6.49, P<0.02)$. During summer days, precipitation tended to increase the time cows spent outside $\left(F_{1,26}=\right.$ $3.11, P=0.090)$ by approximately the same amount $(14.3 \pm 8.1 \% / \mathrm{mm})$. During winter days (for the 7 groups with low time spent outside), precipitation $\left(F_{1,19}\right.$ $=4.51, P<0.05$; slope $-1.2 \pm 0.6 \% / \mathrm{mm})$ and wind speed $\left(F_{1,19}=4.96, P<0.05\right.$; slope $-0.1 \pm 0.1 \% / \mathrm{m}$ per 
second) decreased time spent outside. Of the 2 outlier groups that spent much more time outside, one was tested during the warmest period encountered during the winter experiment (averaging $7.4 \pm 1.5^{\circ} \mathrm{C}$ ), and these 2 groups were the only ones tested in the winter that experienced none or very little precipitation and were only exposed to low wind speeds.

\section{DISCUSSION}

Cows spent about $25 \%$ of their time outside during the summer; this value is lower than that reported in previous studies for pasture access (Legrand et al., 2009; Charlton et al., 2011b, 2013), suggesting that the outdoor pack used in our study was less attractive than pasture. This conclusion is consistent with previous work showing a preference for pasture when cows were provided a choice between pasture and an outdoor sand pack (Smid et al., 2018). Pasture allows cows to engage in grazing behavior, possibly a rewarding activity for cows (Charlton and Rutter, 2017), which may explain this preference. In addition, the space available on the outdoor pack (i.e., $12 \mathrm{~m}^{2}$ per cow) was much smaller than the space on the pasture provided in previous studies (Legrand et al., 2009; Charlton et al., 2011b, 2013). Future work should investigate how space allowances affect preference for outdoor access.

In the summer, cows spent less time outside during the day than during the night, likely to avoid solar radiation (Schütz et al., 2009). During summer days with precipitation cows tended to spend more time outside in our study, potentially because of the cooling effect of precipitation and the reduced solar radiation. Cows spent less time outside during summer nights and winter days with precipitation, which is in line with other studies (Legrand et al., 2009; Charlton et al., 2011a, 2013). The THI (summer) and air temperature (winter) did not affect the amount of time cows spent outside. The lack of an effect may be due to air temperatures that rarely exceeded the lower or upper critical temperature (LCT and UCT, respectively) of cattle. Chase (2011) estimated the LCT of lactating dairy cows to vary between -35 and $-14^{\circ} \mathrm{C}$. The $\mathrm{LCT}$ is dependent on climatic factors (such as wind speed and precipitation) and individual characteristics (such as hair length and type and production level; Boyle et al., 2008). Berman et al. (1985) estimated the UCT of dairy cattle to be around $25^{\circ} \mathrm{C}$; air temperatures above this threshold cause an increase in body temperature that reduces milk production and induces heat stress (Kadzere et al., 2002). Daytime temperatures during the summer occasionally exceeded the UCT, but, on average, temperatures were much lower. Despite temperatures well above the LCT, cows spent little time outside during the winter. It is possible that the combination of various weather conditions (i.e., strong wind in combination with lower temperatures and the presence of snow on the outdoor pack) was aversive to the cows. The 2 groups that spent much more time outside during the winter experienced none or very little precipitation and low wind speeds.

In the summer, but not during the winter, time spent feeding inside the barn was higher during the baseline phase compared with the choice phase, but the difference was small (1.3\%). Legrand et al. (2009) noted a 60-min decline in feeding time at the feed bunk when cows were given free access to pasture for $24 \mathrm{~h} / \mathrm{d}$ as compared with being housed indoors fulltime. That the cows in the current study did not have access to pasture and, hence, had nothing to eat outdoors may explain the lack of difference in feeding time.

Perching was reduced when cows were given access to the outdoor pack during the summer and tended to be lower in the winter. Decreases in perching time when cows were allowed outdoor access are in line with the results of Smid et al. (2018). Bernardi et al. (2009) found a reduction of $16 \mathrm{~min} / \mathrm{d}$ in time spent perching and a $26 \mathrm{~min} / \mathrm{d}$ increase in time spent standing fully in the freestall when cows were provided access to less-restrictive stalls; access to a less-restrictive standing environment also improved gait scores in cows. As the outdoor pack provided cows with a less-restrictive standing environment, they may have preferred to stand outside on the pack decreasing their perching times indoors.

When on the outdoor pack, cows spent about half of the time lying down in the summer. This result is in line with previous work that showed that cows spent approximately $54 \%$ of their time outside lying down (Smid et al., 2018). As suggested by Legrand et al. (2009), the lower lying times often observed when cows are kept on pasture versus freestall housing (e.g., Hernandez-Mendo et al., 2007) may be due to time spent grazing. In addition, both studies suggested that cows might find pasture more comfortable for standing than the concrete flooring found indoors. Indeed, if flooring inside the barn is made more comfortable (Fregonesi et al., 2004; Tucker et al., 2006; Boyle et al., 2007), standing times increase. During the winter experiment, cows spent around $5 \%$ of the time outside lying down. The observation that cows avoid lying down on bedding with high moisture levels (Reich et al., 2010) likely explains this result.

Several potential limitations to the current study exist. One is that options tested (i.e., the freestall barn and the outdoor pack) differed in many ways, so it is difficult to disentangle which factors were important to cows (e.g., TMR was only available indoors). A series 
of experiments where factors are varied individually (i.e., providing cows feed indoors and outdoors, providing cows access to a concrete area outside, and so on) could determine which aspects of the outdoors are most important.

A second limitation relates to the effect of experience. Previous experience with the available options can affect how animals respond when subjected to a preference test (Dawkins, 1977). In the current study, animals were given $2 \mathrm{~d}$ to habituate to the outdoor pack, and this period may not have been sufficient. Tucker et al. (2003) found that animals required long habituation periods (i.e., several weeks to months) to overcome preferences for various types of bedding. Future work should investigate whether longer habituation periods, including having experience as a growing heifer, affect preference for various types of outdoor access. More cows in the winter experiment had experience with the outdoor pack than cows used in the summer experiment; given that the winter cows used the pack less than the summer cows, it would seem that the effects of experience were not so large as to overwhelm the effect of season.

A third limitation was the use of a 5-d test period to investigate preference for outdoor access. Preferences may change over time (Fraser and Matthews, 1997), and we encourage future research to investigate preferences for outdoor access over a longer time span and how access to the preferred environments may affect other aspects of welfare, including health aspects such as mastitis and lameness.

Last, a preference test gives insight into an animals' preference for a specific resource but does not tell us the strength of that preference. When an animal is denied access to a resource for which its preference is strong, welfare is likely more affected than when this preference is weak (Fraser and Matthews, 1997). A motivation experiment can give more insight into the strength of the preference of animals for various resources. A recent study that trained dairy cows to push a weighted gate showed that cows were willing to work as hard to access pasture as they were to access fresh TMR, suggesting that access to pasture is highly valued by dairy cows (von Keyserlingk et al., 2017). We encourage future work to investigate the motivation of dairy cows to gain access to various outdoor areas.

\section{CONCLUSIONS}

During the summer, cows showed a partial preference for the outdoor pack and accessed the pack especially during the night. In the winter, cows showed little interest in accessing the outdoor pack. Access to the outdoor pack decreased perching time compared with when cows were housed indoors, with the effect being the strongest during the summer.

\section{ACKNOWLEDGMENTS}

We thank the staff of The University of British Columbia's Dairy Education and Research Centre for their help with the experiments. We also thank members of the University of British Columbia's Animal Welfare Program, in particular Antoine Buteau, Melissa Jung, Kira Rasmussen, and Savannah Goldstein for their help with the experiments and video analysis. In addition, we thank Agriculture and Agri-Food Canada, Agassiz, BC, Canada, for providing us access to the hourly weather data. A. M. C. Smid was supported, in part, by the Irving K. Barber Victory in Europe scholarship. M. A. G. von Keyserlingk and D. M. Weary are supported by Canada's Natural Sciences and Engineering Research Council (NSERC) via the Industrial Research Chair Program with industry contributions from the Dairy Farmers of Canada (Ottawa, ON, Canada), British Columbia Dairy Association (Burnaby, BC Canada), Westgen Endowment Fund (Abbotsford, BC, Canada), Intervet Canada Corporation (Kirkland, QC, Canada), Zoetis (Kirkland, QC, Canada), Novus International Inc. (Oakville, ON, Canada), BC Cattle Industry Development Fund (Kamloops, BC, Canada), Alberta Milk (Edmonton, AB, Canada), Valacta (St. Anne-de-Bellevue, QC, Canada), and CanWest DHI (Guelph, ON, Canada).

\section{REFERENCES}

Berman, A., Y. Folman, M. Kaim, M. Mamen, Z. Herz, D. Wolfenson, A. Arieli, and Y. Graber. 1985. Upper critical temperatures and forced ventilation effects for high-yielding dairy cows in a subtropical climate. J. Dairy Sci. 68:1488-1495. https://doi.org/10.3168/ jds.S0022-0302(85)80987-5.

Bernardi, F., J. Fregonesi, C. Winckler, D. M. Veira, M. A. G. von Keyserlingk, and D. M. Weary. 2009. The stall-design paradox: Neck rails increase lameness but improve udder and stall hygiene. J. Dairy Sci. 92:3074-3080. https://doi.org/10.3168/jds.2008-1166.

Boyle, L. A., R. M. Boyle, and P. French. 2008. Welfare and performance of yearling dairy heifers out-wintered on a wood-chip pad or housed indoors on two levels of nutrition. Animal 2:769-778. https: //doi.org/10.1017/S1751731108001870.

Boyle, L. A., J. F. Mee, and P. J. Kiernan. 2007. The effect of rubber versus concrete passageways in cubicle housing on claw health and reproduction of pluriparous dairy cows. Appl. Anim. Behav. Sci. 106:1-12. https://doi.org/10.1016/j.applanim.2006.07.011.

Chapinal, N., C. Goldhawk, A. M. de Passillé, M. A. G. von Keyserlingk, D. M. Weary, and J. Rushen. 2010. Overnight access to pasture does not reduce milk production or feed intake in dairy cattle. Livest. Sci. 129:104-110. https://doi.org/10.1016/j.livsci 2010.01.011.

Charlton, G. L., and S. M. Rutter. 2017. The behaviour of housed dairy cattle with and without pasture access: A review. Appl. Anim. Behav. Sci. 192:2-9. https://doi.org/10.1016/j.applanim .2017.05.015.

Charlton, G. L., S. M. Rutter, M. East, and L. A. Sinclair. 2011a. Preference of dairy cows: Indoor cubicle housing with access to a 
total mixed ration vs. access to pasture. Appl. Anim. Behav. Sci. 130:1-9. https://doi.org/10.1016/j.applanim.2010.11.018.

Charlton, G. L., S. M. Rutter, M. East, and L. A. Sinclair. 2011b. Effects of providing total mixed rations indoors and on pasture on the behavior of lactating dairy cattle and their preference to be indoors or on pasture. J. Dairy Sci. 94:3875-3884. https://doi.org/ $10.3168 /$ jds.2011-4172.

Charlton, G. L., S. M. Rutter, M. East, and L. A. Sinclair. 2013. The motivation of dairy cows for access to pasture. J. Dairy Sci. 96:4387-4396. https://doi.org/10.3168/jds.2012-6421.

Chase, L. E. 2011. Stress in dairy animals - Cold stress: Effects on nutritional requirements, health and performance. Pages 550-554 in Encyclopedia of Dairy Sciences. Elsevier, Amsterdam, the Netherlands.

Dawkins, M. 1977. Do hens suffer in battery cages? Environmental preferences and welfare. Anim. Behav. 25:1034-1046. https://doi .org/10.1016/0003-3472(77)90054-9.

Edmonson, A. J., I. J. Lean, L. D. Weaver, T. Farver, and G. Webster. 1989. A body condition scoring chart for holstein dairy cows. J. Dairy Sci. 72:68-78. https://doi.org/10.3168/jds.S0022 -0302(89)79081-0.

Flower, F. C., and D. M. Weary. 2006. Effect of hoof pathologies on subjective assessments of dairy cow gait. J. Dairy Sci. 89:139-146. https://doi.org/10.3168/jds.S0022-0302(06)72077-X.

Fraser, D., and L. R. Matthews. 1997. Preference and motivation testing. Pages 159-173 in Animal Welfare. M. C. Appleby and B. O. Hughes, ed. CAB International, Wallingford, UK.

Fregonesi, J. A., C. B. Tucker, D. M. Weary, F. C. Flower, and T. Vittie. 2004. Effect of rubber flooring in front of the feed bunk on the time budgets of dairy cattle. J. Dairy Sci. 87:1203-1207. https:// doi.org/10.3168/jds.S0022-0302(04)73270-1.

Fregonesi, J. A., M. A. G. von Keyserlingk, and D. M. Weary. 2009 Cow preference and usage of free stalls compared with an open pack area. J. Dairy Sci. 92:5497-5502. https://doi.org/10.3168/ jds.2009-2331.

Galindo, F., and D. M. Broom. 2000. The relationships between social behaviour of dairy cows and the occurrence of lameness in three herds. Res. Vet. Sci. 69:75-79. https://doi.org/10.1053/rvsc.2000 .0391 .

Hernandez-Mendo, O., M. A. G. von Keyserlingk, D. M. Veira, and D. M. Weary. 2007. Effects of pasture on lameness in dairy cows. J. Dairy Sci. 90:1209-1214. https://doi.org/10.3168/jds.S0022 -0302(07)71608-9.

Hötzel, M. J., C. S. Cardoso, A. Roslindo, and M. A. G. von Keyserlingk. 2017. Citizens' views on the practices of zero-grazing and cow-calf separation in the dairy industry: Does providing information increase acceptability? J. Dairy Sci. 100:4150-4160. https:// doi.org/10.3168/jds.2016-11933.

Kadzere, C. T., M. R. Murphy, N. Silanikove, and E. Maltz. 2002. Heat stress in lactating dairy cows : a review. Livest. Prod. Sci. 77:59-91.
Ledgerwood, D. N., C. Winckler, and C. B. Tucker. 2010. Evaluation of data loggers, sampling intervals, and editing techniques for measuring the lying behavior of dairy cattle. J. Dairy Sci. 93:51295139. https://doi.org/10.3168/jds.2009-2945.

Legrand, A. L., M. A. G. von Keyserlingk, and D. M. Weary. 2009. Preference and usage of pasture versus free-stall housing by lactating dairy cattle. J. Dairy Sci. 92:3651-3658. https://doi.org/10 $.3168 /$ jds.2008-1733.

NRC. 2001. Nutrient Requirements of Dairy Cattle. 7th rev. ed. Natl. Acad. Press, Washington, DC.

Ravagnolo, O., I. Misztal, and G. Hoogenboom. 2000. Genetic component of heat stress in dairy cattle, development of heat index function. J. Dairy Sci. 83:2120-2125. https://doi.org/10.3168/jds .S0022-0302(00)75094-6.

Reich, L. J., D. M. Weary, D. M. Veira, and M. A. G. von Keyserlingk. 2010. Effects of sawdust bedding dry matter on lying behavior of dairy cows: A dose-dependent response. J. Dairy Sci. 93:15611565. https://doi.org/10.3168/jds.2009-2713.

Schuppli, C. A., M. A. G. von Keyserlingk, and D. M. Weary. 2014. Access to pasture for dairy cows: Responses from an online engagement. J. Anim. Sci. 92:5185-5192. https://doi.org/10.2527/ jas.2014-7725.

Schütz, K. E., A. R. Rogers, N. R. Cox, and C. B. Tucker. 2009. Dairy cows prefer shade that offers greater protection against solar radiation in summer: Shade use, behaviour, and body temperature. Appl. Anim. Behav. Sci. 116:28-34. https://doi.org/10.1016/ j.applanim.2008.07.005.

Smid, A. M. C., D. M. Weary, J. H. C. Costa, and M. A. G. von Keyserlingk. 2018. Dairy cow preference for different types of outdoor access. J. Dairy Sci. 101:1448-1455. https://doi.org/10.3168/jds .2017-13294.

Tucker, C. B., D. M. Weary, A. M. de Passillé, B. Campbell, and J. Rushen. 2006. Flooring in front of the feed bunk affects feeding behavior and use of freestalls by dairy cows. J. Dairy Sci. 89:20652071. https://doi.org/10.3168/jds.S0022-0302(06)72274-3.

Tucker, C. B., D. M. Weary, and D. Fraser. 2003. Effects of three types of free-stall surfaces on preferences and stall usage by dairy cows. J. Dairy Sci. 86:521-529. https://doi.org/10.3168/jds.S0022 -0302(03)73630-3.

UBC AWP. 2013. University of British Columbia Animal Welfare Program: SOP - HOBO Data Loggers. Pages 1-23. University of British Columbia, Vancouver, Canada. Accessed Aug. 31, 2017. http: //lfs-awp.sites.olt.ubc.ca/files/2013/11/SOP-HOBO-Datalogger -november-2013.pdf.

von Keyserlingk, M. A. G., A. Amorim Cestari, B. Franks, J. A. Fregonesi, and D. M. Weary. 2017. Dairy cows value access to pasture as highly as fresh feed. Sci. Rep. 7:44953. https://doi.org/10.1038/ srep44953. 